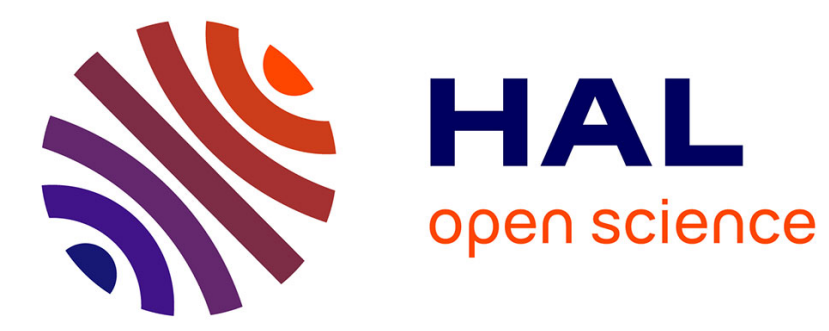

\title{
FEM-Analysis of the One-Dimensional Coupled Thermomechanical Problem of TiNi SMA
}

\author{
A. Ziólkowski, B. Raniecki
}

\section{To cite this version:}

A. Ziólkowski, B. Raniecki. FEM-Analysis of the One-Dimensional Coupled Thermomechanical Problem of TiNi SMA. Journal de Physique IV Proceedings, 1996, 06 (C1), pp.C1-395-C1-403. 10.1051/jp4:1996138 . jpa-00254170

\section{HAL Id: jpa-00254170 https://hal.science/jpa-00254170}

Submitted on 1 Jan 1996

HAL is a multi-disciplinary open access archive for the deposit and dissemination of scientific research documents, whether they are published or not. The documents may come from teaching and research institutions in France or abroad, or from public or private research centers.
L'archive ouverte pluridisciplinaire HAL, est destinée au dépôt et à la diffusion de documents scientifiques de niveau recherche, publiés ou non, émanant des établissements d'enseignement et de recherche français ou étrangers, des laboratoires publics ou privés. 


\title{
FEM-Analysis of the One-Dimensional Coupled Thermomechanical Problem of TiNi SMA
}

\author{
A. Ziółkowski and B. Raniecki \\ Center of Mechanics, Institute of Fundamental Technological Research, PAS Swietokrzyska 21, \\ 00-49 Warszawa, Poland
}

\begin{abstract}
Ahstract: In problem solving regarding SMA materials thermomechanical coupling has to be taken into account due to latent heat of martensitic transformation and heat production resulting from the SMA material internal dissipation processes. Recently there has been developed thermodynamic three dimensional $\mathrm{R}_{\mathrm{L}}$ model of SMA behaviour in pseudoelastic range taking into account relevant transformation kinetic laws of thermoelastic martensitic transformations. In the present paper finite element code with implemented $\mathrm{R}_{\mathrm{L}}$ model constitutive equations has been applied to one-dimensional model of SMA wire sample placed in testing machine. The heat exchange conditions in the form of heat conduction along the wire and heat convection into the surrounding air have been considered. The performed coupled thermomechanical calculations allowed for quantitative evaluation of the influence of the strain rate on the stress-strain curves. The obtained numerical results have been compared with available in the literature experimental data to show sufficiently good quantitative agreement.
\end{abstract}

\section{INTRODUCTION}

Several authors (Ortin [6], Leo et al. [3], Lin et al. [4] and the others) reported on influence of the rate of strain during mechanical tests of SMA samples on the size and shape of hysteresis loop on $\sigma-\varepsilon$ charts. All of them were unanimous to attribute this fact to heat exchange conditions during sample testing. The paper [4] delivers valuable experimental data for $\mathrm{TiNi}$ alloy, theoretical discussion contained in the paper [6] is not concentrated on the dependence of $\sigma-\varepsilon$ curves for $\mathrm{CuZnAl}$ on strain-rate. The theoretical model proposed in paper [3], while delivering theoretical investigation of the observed experimentally by the authors thermomechanical phenomena, does not seem to have broad range of application. It assumes during mechanical loading appearance of only one phase transition interphase moving from one end of the sample to the other (this assumption is confirmed by author's experimental observations at low speed of deformation). This leads them to Stefan like problem with no need for phase transformation kinetic relations. However, according to experimental results specified elsewhere in literature e.g. Olson, Cohen [5], and Huo, Müller [2] appearance of only one interphase during phase transition is not very common situation for SMA alloys. Huo and Müller report in [2], that during single crystal loading they observed several hundred phase interphases. Developed recently by Raniecki, et al. [8], [7] family of $R_{L}$ models describing behaviour of SMA materials in pseudoelastic range delivering adequate kinetic relations of martensitic phase transition have much broader range of application. In Section 2 of the present paper there has been presented field equations resulting from application of $R_{L}$ model constitutive equations and balance laws. Section 3 is devoted to presentation of elaborated by the authors numerical algorithm for search of equilibrium configuration using only symmetric tangent matrix, which has been implemented into originally purely mechanical NONSAP finite element code [1] to solve coupled thermomechanical problem. The geometrical layout, loading program and material data of the investigated problem, which were delivered as an input into modified FEM numerical code are specified in Section 4. The obtained results and their discussion have been presented in Section 5 . 


\section{FIELD EQUATIONS}

\subsection{General Case}

In this section so called $R_{\mathrm{L}}$ (reference with loop) thermodynamical material model constitutive relations developed by Raniecki et al...[8] (see also [7]) are used together with balance equations to obtain governing field equations. The $R_{\mathrm{L}}$ model, which describes thermomechanical behaviour of SMA in pseudoelastic range, is three-dimensional and isotropic. It is rate independent and stipulated to be valid in the range of small strains theory.

The $R_{L}$ model constitutive equations in their rate form are presented below. They consist of four relations: the relation between mean stress rate $\dot{\sigma}_{m}$ and mean strain and temperature rates $\dot{\varepsilon}_{v}, \dot{T}$, tensorial relation between stress and strain deviators rates, kinetic equation of phase transformations and equation for temperature.

The following abbreviate notation is employed below, where $\mathbf{A}$ and $\mathbf{B}$ are two second order tensors and $A_{\text {ij }}$ denote the cartesian components of $\mathbf{A}$ :

$\operatorname{tr} \mathbf{A}=A_{\text {ii }}$

$\mathbf{A} \cdot \mathbf{B}=A_{\mathrm{ij}} B_{\mathrm{ij}} \quad \mathbf{A} \otimes \mathbf{B}=A_{\mathrm{ij}} B_{\mathrm{mn}}$

$\mathbf{1}=\delta_{i j}, \quad \overline{\mathbf{A}}=\mathbf{A}-(1 / 3)(\operatorname{tr} \mathbf{A}) \mathbf{1}$

$\sigma_{m}=(1 / 3)(t r \sigma) ; \quad \varepsilon_{v}=t r \varepsilon$

$\mathbf{I}^{\mathrm{D}}=\left(\delta_{i m} \delta_{m}+\delta_{i n} \delta_{m y}\right) / 2-\delta_{i j} \delta_{m i n} / 3$

$\mathbf{P}(\overline{\mathbf{A}})=1-(\overline{\mathbf{A}} \otimes \overline{\mathbf{A}}) /(\mathbf{A} \cdot \mathbf{A})$

The volumetric part of generalised Hooke's equation in rate form is:

$\dot{\sigma}_{m}=K_{0}\left[\dot{\varepsilon}_{v}-3 \alpha_{0} \dot{T}\right]$

while the shear part of generalised Hooke's equation in rate form is:

$$
\begin{aligned}
& \dot{\bar{\sigma}}=2 \mu_{0}\left(\dot{\bar{\varepsilon}}-\dot{\bar{\varepsilon}}^{p e}\right) \\
& \dot{\bar{\varepsilon}}^{p e}=(\eta / \varepsilon)[\vec{\varepsilon} \dot{z}-z \mathbf{P}(\bar{\varepsilon}) \dot{\bar{\varepsilon}}]
\end{aligned}
$$

where $\varepsilon=\left(\bar{\varepsilon}_{i j} \bar{\varepsilon}_{i j}\right)^{1 / 2} ; z, T$ denote mass fraction of martensitic phase and temperature, whereas $K_{0}, \mu_{0}, \alpha_{0}$, $\rho$ denote respectively elastic bulk modulus, shear modulus, thermal expansion coefficient and mass density of two-phase alloy. The symbol $\eta$ represents the "amplitude" of the pseudoelastic flow in simple shear, whereas $\bar{\varepsilon}^{p e}$ is the tensor of pseudoelastic deviatoric strain $\left(\operatorname{tr} \bar{\varepsilon}^{p e}=0\right)$.

The forward and backward transformations kinetic equation specified in compact form is

$$
\dot{z}=\left(1 / H_{i}^{(1)}\right) \bar{H}\left(\pi^{\prime}\right)<\dot{\tilde{\pi}}_{:}^{\prime}>-\left(1 / H_{\varepsilon}^{(2)}\right) \bar{H}\left(-\pi^{f}\right)<-\dot{\tilde{\pi}}_{\varepsilon}^{\prime}>
$$

where: $\bar{H}(x)=1$ if $x \geq 0$, and $\bar{H}(x)=0$ otherwise. The parenthesis function $\langle x\rangle$ is defined in the form: $\langle\mathrm{x}\rangle=\mathrm{x}$ for $\mathrm{x} \geq 0$, and $\langle\mathrm{x}\rangle=0$ for $\mathrm{x}<0$.

The function $\pi^{\mathrm{f}}$ represents the thermodynamic driving force of the phase transformation. It is shown in Raniecki et al...[8] that the expression $\pi^{\mathrm{f}} \mathrm{dz}$ represents internal energy dissipation in macroelement and thus it has to be non-negative for any $d z \neq 0$. The driving force is the following function of state:

$$
\pi^{\prime}(\sigma, T, z)=\pi_{0}^{f}(T)+\sigma \eta / \rho-\phi_{i t}(1-2 z)
$$


where $\sigma=\left(\bar{\sigma}_{i j} \bar{\sigma}_{i j}\right)^{1,2}, \phi_{i t}(T)=\bar{u}_{0}-T \bar{s}_{0}$, and $\bar{u}_{0}, \bar{s}_{0}$ are material constants connected with internal interactions of both phases. It should be noticed here, that the term $\phi_{i t} z(1-z)$ appearing in free energy function definition postulated for $R_{L}$ model describes in a global form the free energy of internal interactions between the parent and the product phase during ongoing phase transformation (see [8]).

The terms $\dot{\pi}_{\varepsilon}^{\prime}$ and $\mathrm{H}_{s}^{(\alpha)}(\alpha=1,2)$ are defined as follows:

$$
\begin{aligned}
\dot{\tilde{\pi}}_{z}^{\prime} & \equiv\left(\partial \pi^{\prime} / \partial \varepsilon\right) \dot{\varepsilon}+\left(\partial \pi^{\prime} / \partial T^{\prime}\right) \dot{T}=\left(2 \mu_{0} \eta / \rho\right) \dot{\varepsilon}-\left[\Delta s^{*}-\bar{s}_{0}(1-2 z)\right] \dot{T} \\
\mathrm{H}_{v}^{\prime \prime} & =\mathrm{k}_{z}^{\prime \alpha}+\left(2 \mu_{0} \eta^{2} / \rho\right)-2 \phi_{i r}\left(T^{\prime}\right)
\end{aligned}
$$

where $\mathrm{k}_{z}^{\prime \prime}=d \mathrm{k}^{\prime \prime} / d z$, and

$k^{(1)}(z)=-\left[\left(\Delta s^{*}-\bar{s}_{0}+2 r_{1} \bar{s}_{0} z\right) / a_{1}\right] \ln (1-z)+2 r_{1} \phi_{i t}\left(M_{s}^{0}\right) z$

$k^{(2)}(z)=\left[\left(\Delta s^{*}+\bar{s}_{0}-2 r_{2} \bar{s}_{0}(1-z)\right) / a_{2}\right] \ln z-2 r_{2} \phi_{i t}\left(A_{s}^{0}\right)(1-z)$

Here $M_{s}^{0}, A_{s}^{0}$ denote temperatures of the start of forward and backward transformations at stress free state, $a_{1}, a_{2}, r_{1}, r_{2}-$ are phenomenological constants that characterise phase transformation kinetics.

The temperature equation, using Fourier law of heat transfer $\mathbf{q}=-\lambda \nabla T$, is as follows:

$c_{p} \partial T / \partial t+(1 / \rho) \operatorname{div}(-\lambda \nabla T)-\left(\dot{q}_{r}+\dot{r}\right)=0$

where $c_{p}$ is specific heat at constant pressure, $\lambda$ isotropic conductivity coefficient, $\dot{\mathrm{I}}$ mass specific external heat sources, whereas $\dot{q}_{i r}$ denotes heat rate connected with phase transformation (latent heat together with heat of internal material dissipation) and piezocaloric effect

$\dot{q}_{t r}=\left[(\sigma \eta / \rho)+\left(\Delta u^{*}-\bar{u}_{0}(1-2 z)\right)\right] \dot{z}-\left(3 \alpha_{0} T / \rho\right) \dot{\sigma}_{m}$

the symbols $\Delta u^{*}=u_{0}^{*(1)}-u_{0}^{*(2)}, \Delta s^{*}=s_{0}^{*(1)}-s_{0}^{*(2)}$ denote differences between specific internal energies and entropies $u_{0}^{*(\alpha)}, s_{0}^{*(\alpha)}$ of the parent (austenite, $\alpha=1$ ) and the product phase (martensite, $\alpha=2$ ) in the stress free state at the chosen reference temperature $T_{0}$.

The rate form of balance of mechanical equilibrium assuming small gradient of displacements is:

$\operatorname{div} \dot{\sigma}+\rho \mathbf{f}=0$

where $\boldsymbol{i}$ denotes body forces per unit of mass.

Equations (4) and (6) constitute field equations of the thermomechanical rate problem. They must be satisfied identically at any time, in the whole volume of the investigated structure $\mathrm{V}$ and should be augmented with appropriate boundary and initial conditions:

$\mathbf{u}=\mathbf{u}_{\mathrm{s}}(\mathrm{t})$ on $\partial \mathrm{V}_{\mathrm{u}}, \sigma \mathbf{n}=\mathbf{t}_{\mathrm{s}}(\mathrm{t})$ on $\partial \mathrm{V}_{\mathrm{s}}$

$\mathrm{T}=\mathrm{T}_{\mathrm{s}}(\mathrm{t})$ on $\partial \mathrm{V}_{\mathrm{T}}, \mathrm{q}=\mathrm{q}_{\mathrm{s}}(\mathrm{t})$ on $\partial \mathrm{V}_{\mathrm{q}}, \mathrm{q}=\mathrm{h}_{\mathrm{p}}\left(\mathrm{T}_{\mathrm{e}}-\mathrm{T}\right)$ on $\partial \mathrm{V}_{\mathrm{e}}$

$\mathbf{u}(\mathbf{x}, t=0)=\mathbf{u}_{o}, T(\mathbf{x}, t=0)=T_{o,}, z(\mathbf{x}, t=0)=z_{o}$ in $V$

where $\mathbf{n}$ denotes vector normal to the surface of the structure body $\partial \mathbf{V}, \mathbf{q}_{\mathrm{s}}$ heat flux prescribed on the surface of the body, $h$ denotes heat convection coefficient, $T_{e}$ is environment temperature, and $T$ denotes temperature on the surface of the body.

$\mathrm{R}_{\mathrm{L}}$-model demands 9 more material constants $\left(\Delta u^{*}, \Delta s^{*}, \bar{u}_{0}, \bar{s}_{0}, \eta ; \mathrm{a}_{1}, \mathrm{a}_{2}, \mathrm{r}_{\mathrm{h}}, \mathrm{r}_{2}\right)$ in comparison to the usual linear theory of thermoelasticity to characterise the isotropic thermodynamic properties of the SMA material. This material constants can be determined from two standard tension tests performed in two 
different temperatures (above $A_{\mathrm{f}}$ temperature) during which full martensitic transformation occurred at top of mechanical loading.

\subsection{One Dimensional Case}

In one dimensional case the following simplifications ensue. The stress invariant $\sigma=(2 / 3)^{1 / 2} \sigma_{1}$, the volumetric stress $\sigma_{n 1}=(1 / 3) \sigma_{1}$, where $\sigma_{1}=\sigma_{11}$ is the only non zero component of the Cauchy stress tensor, $\varepsilon_{1}=\varepsilon_{11}, \varepsilon_{2}=\varepsilon_{22}=\varepsilon_{3}=\varepsilon_{33}$ are the only non zero components of the strain tensor. The rate equations (1), (2) simplify to

$$
\dot{\sigma}_{1}=E_{0}\left[\dot{\varepsilon}_{1}-\gamma \operatorname{sign}\left(\varepsilon_{1}\right) \dot{z}-\alpha_{0} \dot{T}\right]
$$

where $E_{0}, \gamma$ are Young modulus and "amplitude" of the pseudoelastic flow in simple tension $\left(\gamma=(2 / 3)^{(1 / 2)} \eta\right)$, respectively.

In temperature equation (4) $\operatorname{div}(-\lambda \nabla T)$ is replaced by derivative in respect of one spatial coordinate $d^{2} T / d x^{2}$, while three mechanical equilibrium equations (6) are replaced with simple equation $\sigma_{1}=$ const .

\section{FEM-CODE THERMOMECHANICAL COUPLING ALGORITHM}

The constitutive relations presented in the previous section have been implemented into existing purely mechanical finite element code. We shall not present all the line of this process in here referring the interested reader to book [1] for general background and to work [10] utterly devoted to $\mathrm{R}_{\mathcal{L}}$ model implementation into finite element code. However it might be of interest thermomechanical coupling algorithm which was applied by the authors in FEM code serving for search of equilibrium configuration of loaded thermomechanical structure using only symmetric tangent matrix.

For finite element method purposes the thermomechanical problem defined by field equations (4), (6) together with conditions (7) is transformed into its weak form (see [1]):

$$
\begin{aligned}
& G_{u} \equiv \int_{V} \dot{\sigma} \delta \varepsilon d V^{\prime}-\int_{i} \rho \dot{\mathbf{f}} \delta \mathbf{u} d V^{\prime}-\int_{W} \dot{\mathbf{t}}_{s} \delta \mathbf{u} d a=0 \\
& G_{r} \equiv \int_{V}\left(\rho c_{p} T\right) \delta T d V+\int_{V}(\lambda \nabla T) \delta \nabla T d V-\int_{I^{\prime}} \rho\left(\dot{q}_{t r}+\dot{r}\right) \delta T d V+ \\
& -\int_{N_{*}} \mathrm{q}_{s} \delta T d a-\int_{D V} \mathrm{~h}\left(\mathrm{~T}_{\mathrm{e}}-\mathrm{T}\right) \delta T d a=0
\end{aligned}
$$

As the equations (9) are highly nonlinear the most appropriate step in order to find transients satisfying them identically in every moment is to use incremental in time procedure. When implicit modified NewtonRaphson scheme will be accepted, consistent linearization of the weak form equations and subsequent discretization in space and time lead to the set of algebraic equations for temperature and displacement increments for the consecutive time steps. Introduced linearization results usually in some solution error, which accumulates especially over many time steps, that is why so called equilibrium iterations are used in order to safeguard minimal error accumulation. The iterative incremental algebraic equations obtained as a result of described above procedure for thermomechanical problem given in matrix form are as follows:

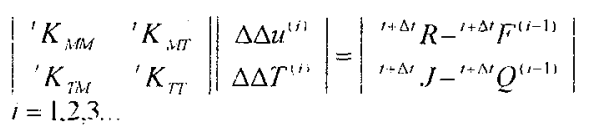

in here $\Delta \Delta u^{\prime \prime \prime}, \Delta \Delta T^{\prime \prime \prime}$ denote vectors of $\mathrm{i}$-th corrections to the displacement and temperature increments for time $\mathrm{t}+\Delta \mathrm{t},{ }^{i+\Delta t} R,{ }^{t+\Delta t} . J$ are vectors of external forces and heat fluxes, ${ }^{t+\Delta t} F^{(i-1)},{ }^{t+\Delta t} Q^{(i-1)}$ are vectors of (i-1) approximations of internal forces and heat fluxes. Iterations are performed until right hand side of set (10) is equal to zero within prescribed tolerance, physically meaning that internal and external forces and heat 
fluxes are balanced. The $\mathrm{K}_{\mathrm{MM}}, \mathrm{K}_{\mathrm{MT}}, \mathrm{K}_{\mathrm{TM}}, \mathrm{K}_{\mathrm{TT}}$ are tangent matrices resulting from linearization and discretization of equilibrium equations (9). The first subscript denotes the effect while the second the cause of mechanical (M) or thermal (T) character. The submatrix $K_{M T}$ is not identical with submatrix $K_{T M}$. This means that global tangent matrix of coupled thermomechanical problem is non-symmetric. Our target was to use symmetric matrix in the solution procedure as solvers for sets of algebraic equations with symmetric matrices are by far most popular and efficient. When temperature is kept constant during mechanical solution phase and geometry is kept constant during thermal solution phase the terms connected with submatrices $\mathrm{K}_{\mathrm{MT}}$ and $\mathrm{K}_{\mathrm{TM}}$ disappear, respectively. This observation dictated global solution strategy presented in Table I below:

Table 1: Staggered solution scheme

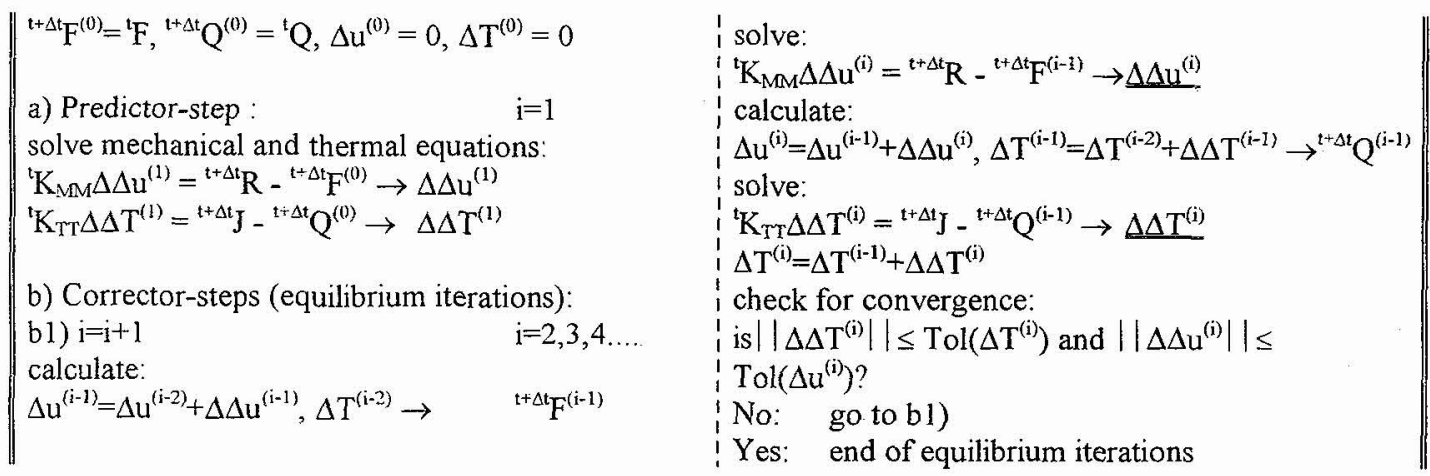

Presented in Table I staggered solution procedure demands only symmetric tangent matrix, allowing reduction of computer memory requirements. However, this does not come without cost. Due to neglect of coupling terms convergence properties of Newton-Raphson method cannot be in here achieved.

\section{NUMERICAL MODEL AND MATERIAL DATA}

In order to investigate the rate of deformation on the size and shape of hysteresis loop the wire specimen made of TiNi placed in testing machine has been modelled in one dimensional fashion. The finite element dicretization of the wire with length $\mathrm{l}=110 \mathrm{~mm}$ and diameter $\mathrm{d}=0.75 \mathrm{~mm}$ (this corresponds to the length between grips and external diameter of specimen used by Lin et al. [4] ) together with surrounding air is shown in Figure 1. Due to symmetry only half of the wire has been discretized. Elements 1-14 are made of SMA material, while those with numbers 15 - 28 model surrounding air (they give no mechanical response). It has been assumed that heat is transferred to the air by natural heat convection with heat convection coefficient $h_{p}=20\left[\mathrm{~W} / \mathrm{m}^{20} \mathrm{~K}\right]$.

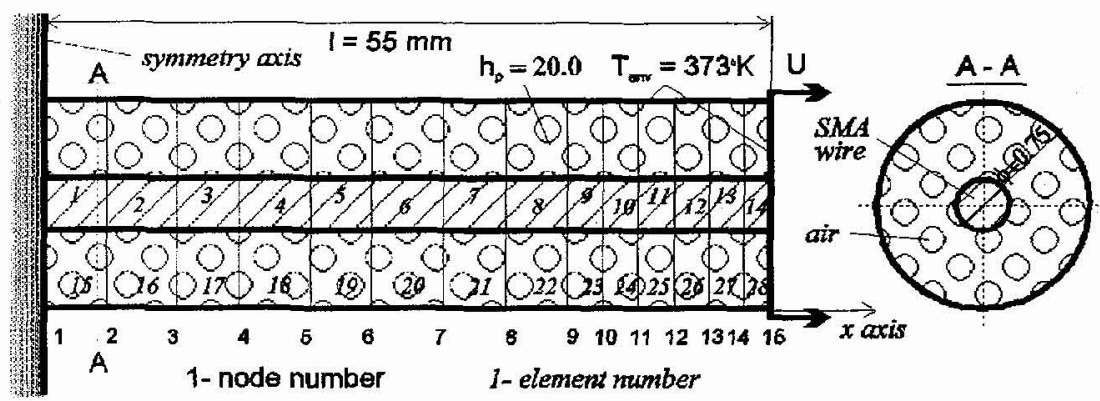

Figure 1: Finite element mesh and data of the wire 
Heat released to the air by convection is taken into account in one dimensional model using heat sources term $\dot{r}$ (equation (4)), which is defined as $\dot{r}=h_{p}\left(T_{e}-T(x, t)\right) A_{s}$ where $\mathrm{A}_{\mathrm{s}}=\pi \mathrm{d}\left[\mathrm{m}^{2} / \mathrm{m}\right]$ is side surface of a cylindrical shape per unit of length along its axis. At the start of loading process the fields $\varepsilon(x, t)=\sigma(x, 0)=z(x, 0)=0, T(x, 0)=373^{\circ} \mathrm{K}\left(\right.$ see $\left.(7)_{3}\right)$.

The boundary conditions are as follows:

$\mathrm{u}(\mathrm{x}=0, \mathrm{t})=0, \mathrm{u}(\mathrm{x}=\mathrm{l}, \mathrm{t})=\mathrm{u}_{\max } \mathrm{t}$ (where $\mathrm{t}$ is time like parameter see Fig. 2)

$\mathrm{q}(\mathrm{x}=0, \mathrm{t})=0, \mathrm{~T}(\mathrm{x}=1, \mathrm{t})=\mathrm{T}_{\mathrm{e}}(\mathrm{t})=373^{\circ} \mathrm{K}$

The process of loading has been simulated with several mean strain rates i.e. $1 \% / \mathrm{min}, 10 \% / \mathrm{min}, 100 \% / \mathrm{min}$ $\left(1.667 \mathrm{e}-4 \mathrm{~s}^{-1}, 1.667 \mathrm{e}-3 \mathrm{~s}^{-1}, 1.667 \mathrm{e}-2 \mathrm{~s}^{-1}\right)$. In order to distinguish characteristic features of the phenomenon loadings were performed to $8 \%$ maximum strain, while in order to compare numerical results with experimental data additional loading at $100 \% / \mathrm{min}$ was performed to $6 \%$ maximum strain.

\begin{tabular}{|l|c|l|c|}
\hline $\begin{array}{l}\text { The material } \\
\text { data }\end{array}$ & $\begin{array}{l}\text { TiNi } \\
\text { polycrystal }\end{array}$ & $\begin{array}{l}\text { The material } \\
\text { data }\end{array}$ & $\begin{array}{l}\text { TiNi } \\
\text { polycrystal }\end{array}$ \\
\hline$\rho\left[\mathrm{kg} / \mathrm{m}^{3}\right]$ & 6500 & $\mathrm{a}_{1}[1 / 0 \mathrm{~K}]$ & 0.09 \\
\hline $\mathrm{E}[\mathrm{MPa}]$ & $59150)$ & $\mathrm{a}_{2}[1 / 0 \mathrm{~K}]$ & 0.25 \\
\hline$\gamma$ & 0.064 & $\mathrm{r}_{1}$ & 0.85 \\
\hline$\Delta \mathrm{ll}^{*}[\mathrm{~J} / \mathrm{kg}]$ & 17050 & $\mathrm{r}_{2}$ & 1.0 \\
\hline$\Delta \mathrm{s}^{*}[\mathrm{~J} / \mathrm{kg}$ OK] & 60.3 & $\mathrm{c}_{\mathrm{p}}[\mathrm{J} / \mathrm{kgOK}]$ & 530 \\
\hline $\bar{u}_{0}[\mathrm{~J} / \mathrm{kg}]$ & 3077 & $\lambda[\mathrm{W} / \mathrm{moK}]$ & 20 \\
\hline $\bar{s}_{0}[\mathrm{~J} / \mathrm{kg}$ OK] & 3.69 & & \\
\hline
\end{tabular}

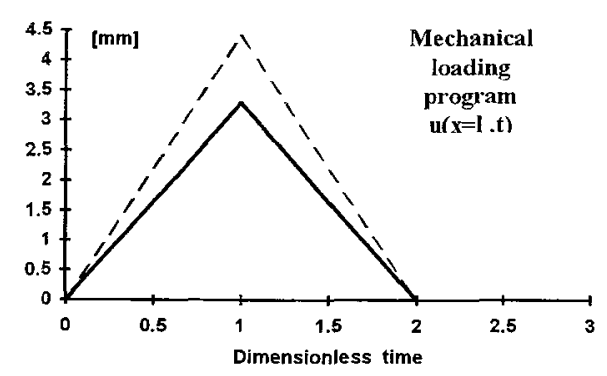

Figure 2: TiNi material data and mechanical loading program

The time step of the numerical solution has been chosen to be $\Delta t=0.0125 \mathrm{~s}$. Material data for not trained polycrystalline TiNi alloy used for numerical simulation were identified on the base of experimental data delivered in paper [9] and are presented in the table on Figure 2.

\section{NUMERICAL RESULTS AND DISCUSSION}

In this section results of numerical simulations, their discussion and comparison with experimental results have been presented. In Figures 3 and 4 comparisons of numerical results with experimental one, that presented in paper [4] are shown. The stress-strain curves are for element 1 (see Figure 1). First of all the reader can notice that experimental curves are not closed loops, while those numerical are. The reason for that lies in the fact that $\mathrm{R}_{\mathrm{L}}$. model has been developed rather for already stabilized SMA material (e.g. trained) where the response is in the form of closed hysteresis loops which appear after a dozen or so loading-unloading cycles. The second discrepancy results from the fact that $\mathrm{R}_{\mathrm{L}}$ model [8] does not very precisely describe an early nucleation stage of forward and reverse transformation. For the third, elastic modulus is considerably different for austenitic and martensitic phase of TiNi alloy. Improvements to this modelling drawbacks have already been made in later work [7]. Having the above on mind agreement of isothermal curves in Figure 3 is good. In Figure 4 where rate of sample deformation was kept at 100\%/min good agreement can be observed on upper parts of experimental and numerical curves. Disagreement on lower parts according to authors suspects result from very strong microstructural changes in the material. Much better agreement is expected for tests on trained TiNi alloy samples. However, no experimental data for such samples deformed with different rates of deformation were available to the authors. 


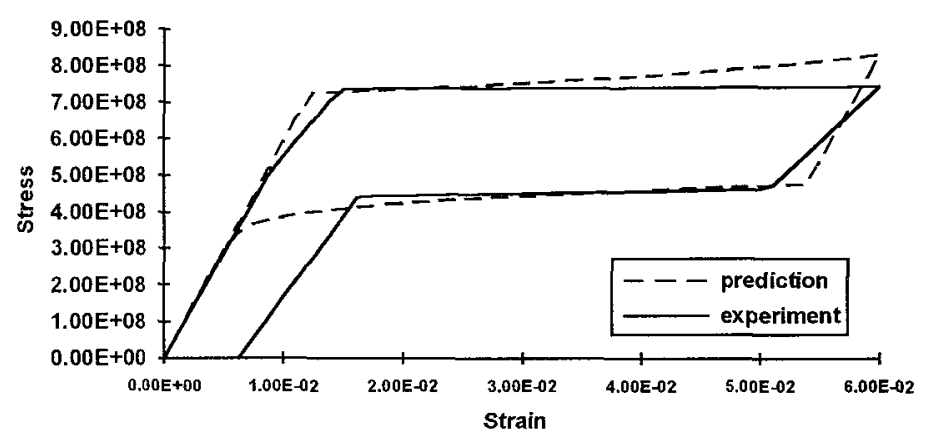

Figure 3: Comparison of experimental and numerical results for isothermal case; calculated maximum phase transformation $z_{\max }=0.717 ; \varepsilon_{\max }=6 \%$

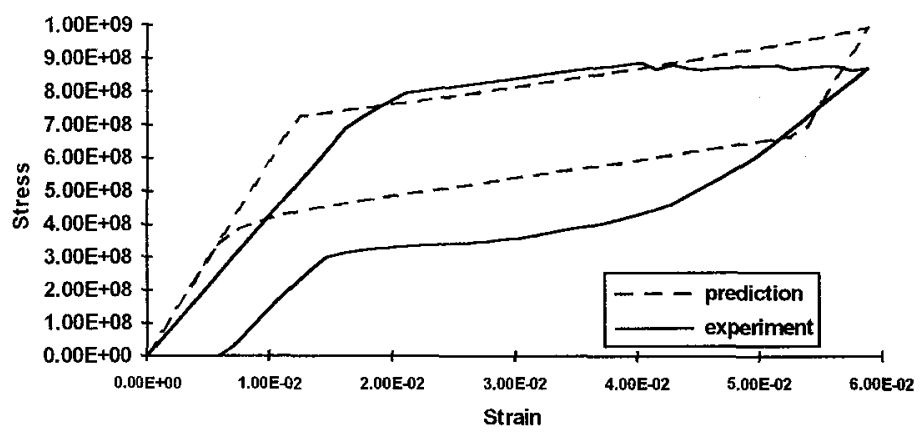

Figure 4: Comparison of experimental and numerical results for $\dot{\varepsilon}=100 \% / \mathrm{min}$; calculated maximum phase transformation $Z_{\max }=0.657 ; \varepsilon_{\max }=6 \%$

In Figure 5 comparison of numerical results for three different rates of deformations i.e. $1 \%, 10 \%$ and $100 \%$ per minute have been shown. The modelled samples were deformed to reach approximately $8 \%$ strain. The very characteristic features of influence of the heat exchange conditions on hysteresis loop can now be clearly observed. Two limit case are shapes of isothermal and adiabatic loops. Performed by authors numerical simulations for TiNi wire indicated that $100 \%$ rate of deformation loop is very close to that of adiabatic, while $1 \%$ rate of deformation loop is nearly identical with that of isothermal. It can be noticed that the location of isothermal loop raises and it thickens with increase of rate of deformation, subsequently it attains maximum size and then becoming thinner and slanted takes the shape of adiabatic hysteresis loop.

Finally, Figures 6 and 7 depict spatial distributions of martensitic phase fraction and temperature along the wire at several time instants. As can be seen in Figure 6, the transformation progresses the most quickly at the machine grip during forward transformation. However, during reverse transformation a peak of martensitic phase is formed at the location of element 13. 


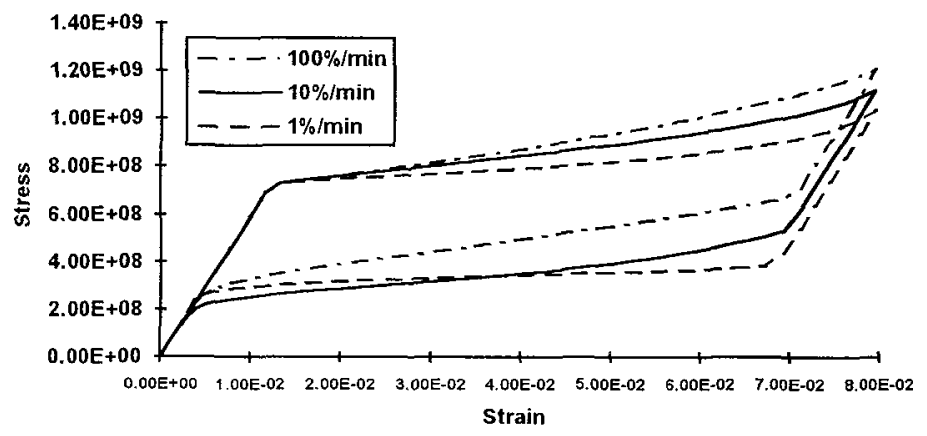

Figure 5: Comparison of numerical results for three different rates of deformation $\dot{\varepsilon}=1 \% / \min , 10 \% / \min , 100 \% / \min ; z_{\max 100 \%}=0.924, z_{\max 10 \%}=0.942, z_{\max 1 \%}=0.975 ; \varepsilon_{\max }=8 \%$

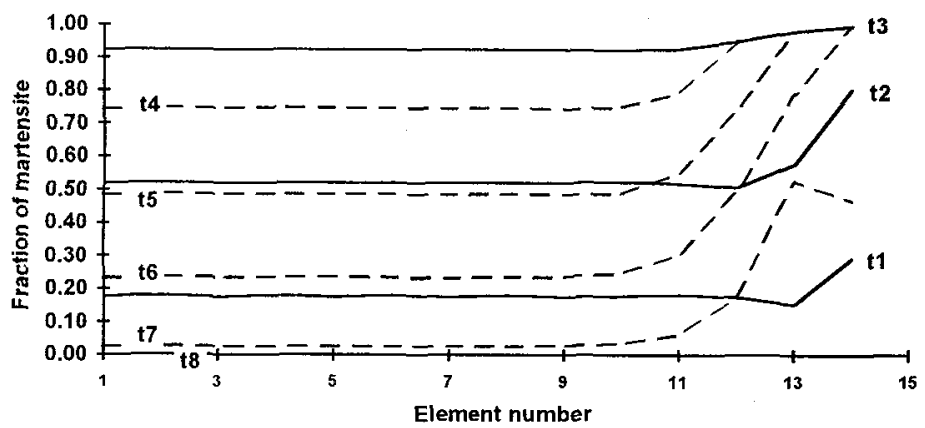

Figure 6: Phase fraction as function of $\mathrm{x}$ for several time instants; $\dot{\varepsilon}=100 \% / \mathrm{min} ; \varepsilon_{\max }=8 \%$ $\left(t_{1}=1.5 \mathrm{~s}, \mathrm{t}_{2}=3.0 \mathrm{~s}, \mathrm{t}_{3}=4.8 \mathrm{~s}, \mathrm{t}_{4}=6 \mathrm{~s}, \mathrm{t}_{5}=7 \mathrm{~s}, \mathrm{t}_{6}=8 \mathrm{~s}, \mathrm{t}_{7}=9 \mathrm{~s}, \mathrm{t}_{8}=9.6 \mathrm{~s}\right)$

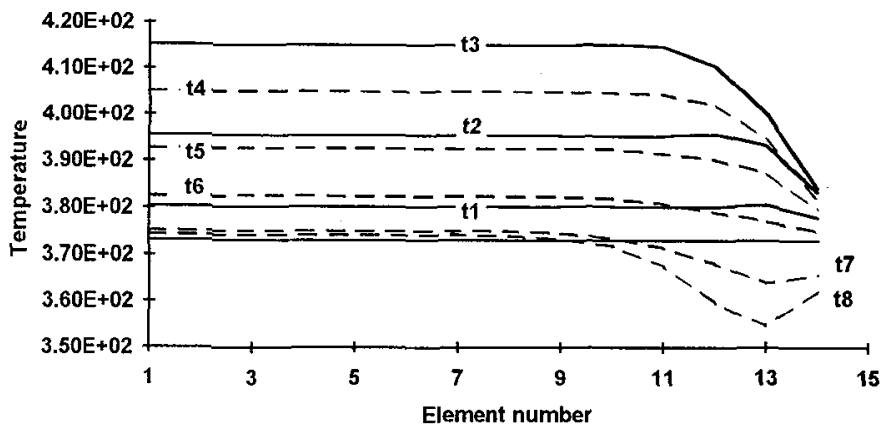

Figure 7: Temperature distribution corresponding to that of phase fraction presented in Fig. 6 ; $\dot{\varepsilon}=100 \% / \min ; \varepsilon_{\max }=8 \%$ 


\section{CONCLUSION}

In the present paper influence of strain rate on size and shape of hysteresis loop for SMA TiNi material has been investigated. For this purpose finite element code with implemented $R_{L}$ model constitutive relations and special equilibrium search algorithm has been applied to simulate one-dimensional thermomechanical behaviour of SMA wire during testing. The obtained numerical results showed that in fact change of size and shape of hysteresis loop with rate of deformation to considerable extent can be attributed to heat exchange conditions prevailing during testing $\left(\mathrm{R}_{\mathrm{l}}\right.$, model equations are rate insensitive). It seems that better compatibility between experiment and simulation using $\mathrm{R}_{\mathrm{L}}$ model would be obtained for trained SMA materials. Numerical simulations also indicated that for TiNi alloy wire in testing machine heat transfer through heat conduction plays insignificant role in comparison to heat convection.

\section{Acknowledgements}

The present work was financially supported by the State Committee for Research (KBN) in Poland, Project No. 3P40403507.

\section{References}

[1] Bathe K.J., Finite Element Procedures in Engineering Analysis (Prentice-Hall, Inc., Englewood Cliffs., New Jersey 07632, 1982).

[2] Huo Y., Müller I., Nonequilibrium Thermodynamics of Pseudoelasticity, Continuum Mech Thermodyn.,5(3), (1993), p.163

[3] Leo P.H. Shield T.W., Bruno O.P., Transient heat transfer effects on the pseudoelastic behavior of shape memory wires. Acta Metall. Mater 41(8), (1993), pp 2477-2485.

[4] Lin P., Tobushi H., Tanaka K, Hattori T., Influence of strain rate on deformation properties of TiNi Shape Memory Alloy, JSME 33(2), (1990), pp.263-268.

[5] Olson G.B., Cohen M.(ed.), Martensite, A Tribute to Morris Cohen, (ASM International, 1992).

[6] Ortin J., Preisach modelling of hysteresis for a pseudoelastic CuZnAl single crystal, J.Appl.Phys., 71(3), (1992), pp. 1454-1460.

[7] Raniecki B., Lexcellent C., $R_{L}$ - models of pseudoelasticity and their specifications for some shape memory alloys, Europ. J. of Mechanics /Solids/,1(13), (1994), pp. 1-30.

[8] Raniecki B., Lexcellent C., Tanaka K., Thermodynamic models of pseudoelastic behaviour of shape memory alloys, Arch. Mech., 44 (3), (1992), p.261.

[9] Tobushi H., Iwanaga H., Tanaka K, Hori T., Sawada.T, Deformation behaviour of TiNi shape memory alloy subjected to variable stress and temperature, Continuum Mech. Thermodyn. 3, (1991), pp.79-93.

[10] Ziółkowski A., Raniecki B., FEM-based formulation of the coupled thermomechanical problems of Shape Memory Alloys, in Proceedings of the Japan-Central Europe Joint Workshop on Advanced Computing in Engineering, Pultusk 26-29 September, M. Akiyama and M. Kleiber Eds. IPPT PAN, Warsaw, Poland 1994) p.207 